\title{
Index of the Cycle of Money: The Case of Serbia
}

\author{
Constantinos Challoumis \\ National and Kapodistrian University of Athens, GREECE \\ School of Economics and Political Sciences
}

Received: 1 December 2020 - Accepted: 28 March 2021 - Published Online: 1 May 2021

\begin{abstract}
This paper sought to make clear how the concept of the cycle of money works in an actual case scenario like this of the economic system of Serbia. The index of the cycle of money suggests how an economic system ought to counteract an economic crisis and studies how well-structured is a country's economy. The estimations of the index of the cycle of money of Serbia are compared with the global average index of the cycle of money. The estimations reveal that Serbia belongs to medium rate according to the average global value. Serbia results reveal that it is a fine structured economy and can face an economic crisis, with a moderate dynamic. The applied methodology based on the analysis of theory, mathematical, statistical, and econometrical results. Moreover, this is first published work for Serbia according to this theory and is part of a project that examines the cycle of money of multiple countries.
\end{abstract}

Keywords: Serbia, cycle of money, index of the cycle of money.

\section{The cycle of money of Serbia}

This paper examines the dynamic of the economy of Serbia, using the concept of the cycle of money. The theoretical background of the cycle of money supports that the dynamic of an economy is based on the idea of the number of times that money is used in an economy. An economy should be considered not as a closed system, but as a system with fragments. An amount of money in many cases is getting out from an economy to external banks, or other economies. The mainstream is that the bigger companies and the international companies in most cases are saving their money to external banks and economic heavens. Therefore, according to this theory, the tax authorities should put an additional tax on this kind of companies to decline the losses to the economy. Moreover, the smaller companies and the freelancers should be taxed with lower tax rates. Then, it would be plausible to increase the dynamic of the economy. Also, the factories, the know-how services of big companies, the health care system, and the educational system comprise a special case for the economy, as belong to those cases where the taxes improve the quality of the economy. The factories and the big know-how companies increase the cycle of money, as they do not substitute the activities of the small-medium companies and the freelancers. The educational and health care systems improve the quality of the economy, making the whole economy better. Therefore, this paper sought to make clear how the concept of the cycle of money, works in an actual case scenario like this of the economic system of Serbia. The index of the cycle of money suggests how an economic system ought to counteract a monetary crisis and examines how wellstructured is a country's economy. The calculations of the index of the cycle of money of Serbia are compared with the global average index of the cycle of money. The estimations reveal that Serbia

(C) Authors. Terms and conditions of Creative Commons Attribution 4.0 International (CC BY 4.0) apply. Correspondence: Constantinos Challoumis, Xenarhou 2, Athens, GREECE. E-mail: challoumis constantinos@yahoo.com. 
is close to the average global value. Serbia results show that it is a well-structured economy and can face an economic crisis. The applied methodology stands on the analysis of the theory, mathematical, statistical, and econometrical results.

The concept of the cycle of money reveals that the taxes return to the economy, to the case of the education and the health care system. But the mainstream is that the tax authorities should maintain the taxes to the lowest level. For small and medium companies, the government should protect them with very low taxes, and contemporaneously should put greater taxes on the larger companies. But there is a type of big and international companies that should have low tax rates, as these types of companies are not substituting the activities of smaller companies. These types of big companies are factories and technological know-how companies. Then, the principal idea is to have a financial system, with the best allocation of production (Helpman \& Krugman, 1989). Larger companies should not provide similar products and services, like that of smaller companies, as they can make investments in economic fields that smaller companies cannot support. In that way, an economic system achieves its best level. Additionally, the idea of the cycle of money shows that with the appropriate allocation of production units and of taxes the money is cycled inside the economy achieving the maximum dynamic of the economy. This paper is about Serbia's s index of the cycle of money. The research is based on an actual case scenario of a country's economic system. Therefore, the principal hypothesis of this paper aims to estimate the index of the cycle of money of Serbia and to answer the question if it's near the worldwide general index of the cycle of money, according to the simple index or the general index of the cycle of money. The applied approach is based totally on mathematical estimations from the relevant theory. The results confirmed that Serbia's economic system is properly established, as it follows the general international index of the cycle of money (the value of 0.5 ) which represents the average global case (Challoumis, 2018a) The countries near 0.5 and above it has an appropriate distribution of money to their financial system. Consequently, Serbia's economic system is considered as well established, standing on the results of this paper. The question about the way that works the index of the cycle of money to the case of Serbia is answered from the structure of its economy and the way that distributed the money to its economy. Besides, it needs some improvements to have an even better index cycle of money. Therefore, Serbia should decrease taxes for small and medium enterprises, to achieve better reuse of money in the country's economic system, and to increase taxes to big and international (OECD, July 2017).

\section{Literature review}

The arm's length principle is the principle where the authorities use to apply the taxes to international and to groups of companies. The arm's length principle is the method that the tax authorities estimate the tax obligations of the companies, which participate in international transactions (IMF, 2018).

The authorities using the arm's length principle is tough to obtain the controlled transactions, as the international companies offer similar data with that of the uncontrolled transactions and they are hiding with a purpose to avoid paying taxes. Therefore, the government needs to apply the fixed-length principle. The fixed-length principle indicates that the companies of controlled transactions manage transactions and achieve to avoid tax paying. Then, according to the fixed-length principle, international companies should pay plus a fixed amount of tax (IMF, World Bank \& WTO, 2017) In that way, the cycle of money is enhanced, because the larger companies generally receive the money out the society and the economy and save them to international banks. Therefore, that money is lost from society, making weaker consumption. Then, according to the fixed-length principle, the local companies which save their money to local banks should have lower tax rates. 
Concluding, the fixed-length principle serves the theory of the cycle of money, where the small and medium companies are paying lower taxes than the larger companies, which substitute their commercial activities. On the other hand, the arm's length principle estimates the taxes standing on methodologies provided by the companies that make international transactions. In that way, the large companies cover the activities of the smaller companies. Finally, the mainstream is that small and medium companies robust the distribution of money to a country's economy as usually they don't save their money out of the country's economic system, and reuse the money inside the economy. Therefore, the money distributed inside the economy many times increases the cycle of money.

$$
\begin{gathered}
\text { 3. Methodology } \\
c_{y}=c_{m}-c_{\alpha} \\
c_{y}=\frac{d x_{m}}{d m}-\frac{d x_{m}}{d a} \\
i_{c y}=Y * b_{d} \\
g_{c y \text { Country }}=\frac{c_{y \text { coyntry's }}}{c_{y \text { Average }+c_{y \text { coyntry's }}}} \\
g_{\text {cy Average }}=\frac{c_{y \text { Average }}}{c_{y \text { Average }}+c_{y} \text { Average }}=0.5
\end{gathered}
$$

The $c_{m}$ is the velocity of financial liquidity, $c_{\alpha}$ is the velocity of escaped savings and $c_{y}$ is the cycle of money. The $i_{c y}$ is the index of the cycle of money, $Y$ is the national income or GDP, and $b_{d}$ is the bank deposits of the country. Moreover, $g_{c y \text { country }}$ symbolizes the general index of $c_{y}$ of the country, $c_{y \text { coyntry's }}$ is the index of $c_{y}$ of the country, and $c_{y}$ Average is the global index of $c_{y}$. Finally, $g_{c y \text { Average }}$ is the general global index of $c_{y}$, and is obtained as a global constant.

Therefore, the main hypothesis is to establish the connection between the index of global average $c_{y}$, the bank deposits and the GDP per capita, with an econometric approach. Then is confirmed the initial hypothesis that the cycle of money of Serbia is close to the global average index of the cycle of money.

\section{Results: The case of Serbia}

Standing on the prior methodology extracted the following results. This table includes the parameters of bank deposits, GDPs, and the indexes of the cycle of money. This section reveals the dependence of Serbia's index of the cycle of money using the bank deposits of Serbia's economy and the GDP per capita of Serbia's economy. The bank deposits of the global average case and the global GDP per capita are used for the comparison of Serbia's economy, on its GDP, and the country's bank deposits.

The same conclusions come up and from an econometric point of view, with the dependent variable to be the index of the cycle of money. 
Table 1. Serbia's regression analysis (Source: author's compilation)

\begin{tabular}{|l|l|l|l|}
\hline Variable & Coefficient & std. error & p-value \\
\hline Constant & -228317 & 28943.2 & 0.0157 \\
\hline Serbia's bank deposits & 40.4342 & 1.02970 & 0.0006 \\
\hline Serbia's GDP per capita & 5755.89 & 415.761 & 0.0052 \\
\hline Global index of cycle of money & -0.281025 & 0.748622 & 0.7434 \\
\hline
\end{tabular}

To the prior table, the values with two asterisks symbolize the cases that the coefficients are below the 0.05 significant level, and accordingly the three asterisks the case of 0.01 significant level.

The indexes reveal Serbia's distribution of money and the form of its economic structure. The first three rows of the table reveal that the p-value is important, therefore the initial hypothesis rejected and the model is accurate. The fourth row is expected to be above the $0.1 \mathrm{p}$ value as the global index of cycle of money is independent from any country's rate, as to the most cases, a country has a very small amount to the aggregate value. Based on those estimations and the theoretical background is determined the condition of the economic structure of the country and if Serbia belongs to the good economies. According to these results, it's plausible to clarify the condition of the cycle of money in Serbia (bank deposits of years 2016 and 2017 are waved according to the trend of prior years, because of lack of official data):

Table 2. Serbia's index of the cycle of money

(Source: Globaleconomy.com and author's compilation)

\begin{tabular}{|l|l|l|l|l|l|l|}
\hline & $\begin{array}{l}\text { Bank } \\
\text { Deposits } \\
\text { Global } \\
\text { Average } \\
\text { (\%) }\end{array}$ & $\begin{array}{l}\text { Bank } \\
\text { Deposits } \\
\text { Serbia } \\
\text { (\%) }\end{array}$ & $\begin{array}{l}\text { Global } \\
\text { GDP per } \\
\text { Capita (\$) }\end{array}$ & $\begin{array}{l}\text { Serbia's } \\
\text { GDP per } \\
\text { Capita (\$) }\end{array}$ & $\begin{array}{l}\text { Index of Global } \\
\text { Average Cy (\$) }\end{array}$ & $\begin{array}{l}\text { Index of } \\
\text { Serbia's Cy (\$) }\end{array}$ \\
\hline $\mathbf{2 0 1 2}$ & 52.48 & 40.3 & $16,653.01$ & $14,941.76$ & $873,949.96$ & $602,152.93$ \\
\hline $\mathbf{2 0 1 3}$ & 53.96 & 40.02 & $17,266.62$ & $15,448.96$ & $931,706.82$ & $618,267.38$ \\
\hline $\mathbf{2 0 1 4}$ & 55.81 & 41.99 & $17,159.02$ & $15,274.94$ & $957,644.91$ & $641,394.73$ \\
\hline $\mathbf{2 0 1 5}$ & 59.38 & 43,24 & $15,295 \cdot 71$ & $15,627.95$ & $908,259.26$ & $675,752,56$ \\
\hline $\mathbf{2 0 1 6}$ & 60.77 & 43,61 & $15,330.03$ & $16,234.50$ & $931,605.92$ & $707,986.55$ \\
\hline $\mathbf{2 0 1 7}$ & 60.07 & 43.64 & $15,082.49$ & $16,664.06$ & $906,005.17$ & $727,219.58$ \\
\hline RESULTS & & & & & $\mathbf{5 , 5 0 9 , 1 7 2 . 0 4}$ & $\mathbf{3 , 9 7 2 , 7 7 3 . 7 2}$ \\
\hline
\end{tabular}

For Serbia's bank deposits:

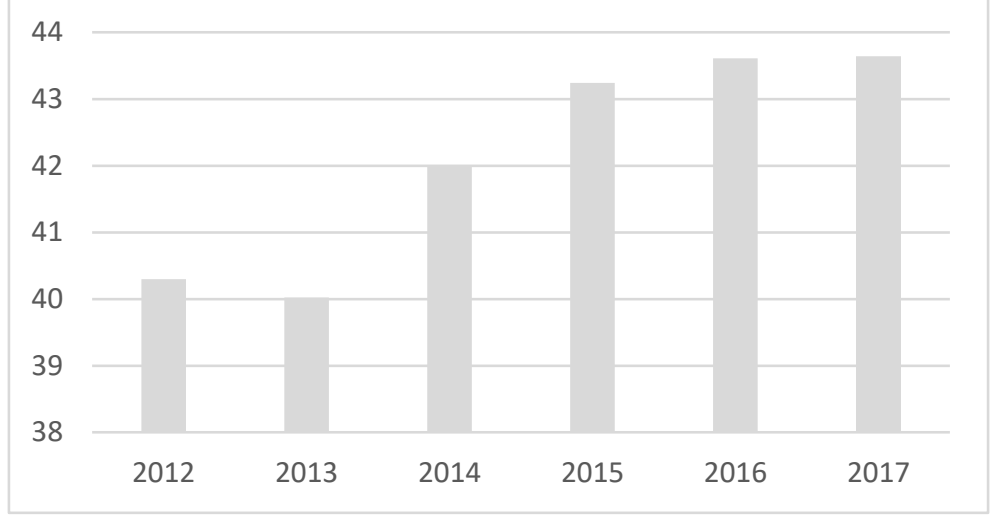

Figure 1. Serbia's bank deposits per GDP (Source: Globaleconomy.com) 
To Figure 1 presents the situation of bank deposits of Serbia's financial system, as a percent of GDP, for the period from 2012 to 2017. Moreover, the next scheme presented the GDPs of Serbia:

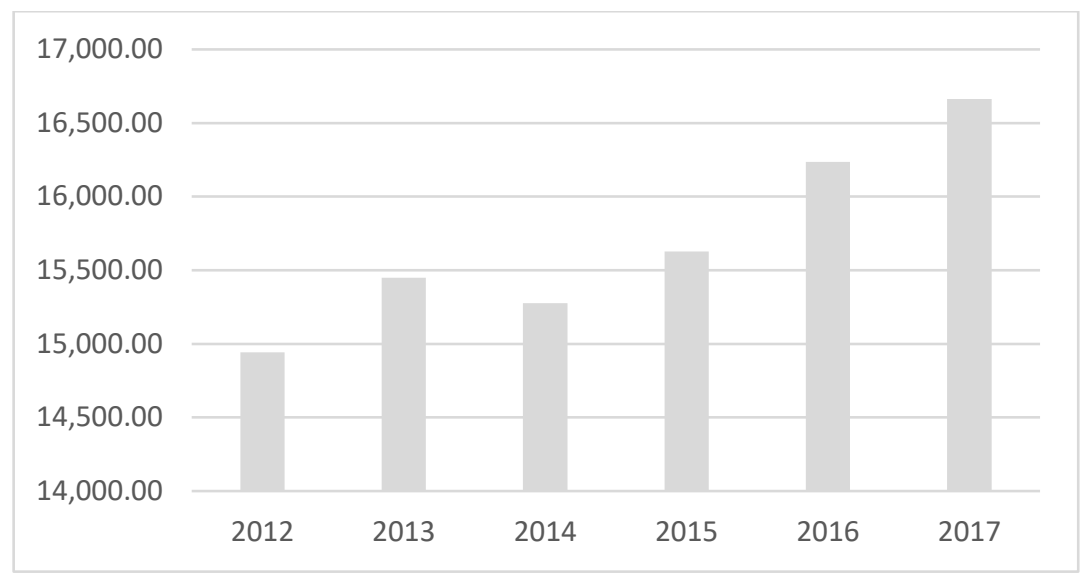

Figure 2. Serbia's GDPs per capita (Source: Globaleconomy.com)

Figure 1 presents the condition of GDPs of Serbia's economy for the period from 2012 to 2017. Also, the next scheme presents the GDPs of Serbia, for the same period.

According to the prior results, the index of Serbia's $c_{y}$ is 3,972,773.72 \$

We obtain from the prior results that:

The index of global average $c_{y}$ is 5,509,172.04 \$

Calculating the general index of the cycle of money for the case of Serbia and of global view we have that:

- The general index of $c_{y}$ for Serbia is $g_{\text {cy country }}=0.419$

- The general index of $c_{y}$ of global view is $g_{c y \text { Average }}=0.5$

Therefore, it is concluded that Serbia's index cycle of money is close to the global average cycle of money. Then, the dynamic of Serbia's economy complies with the global average and its structure is near to the initial hypothesis. Then we receive the next scheme:

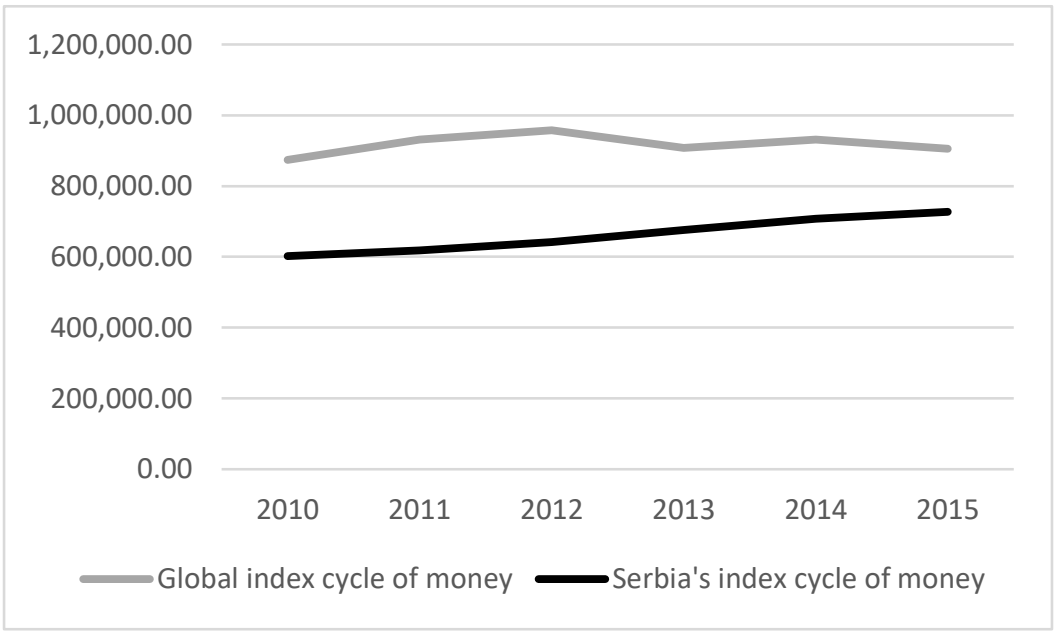

Figure 3. Graph of the index of the cycle of money (Source: author's compilation) 


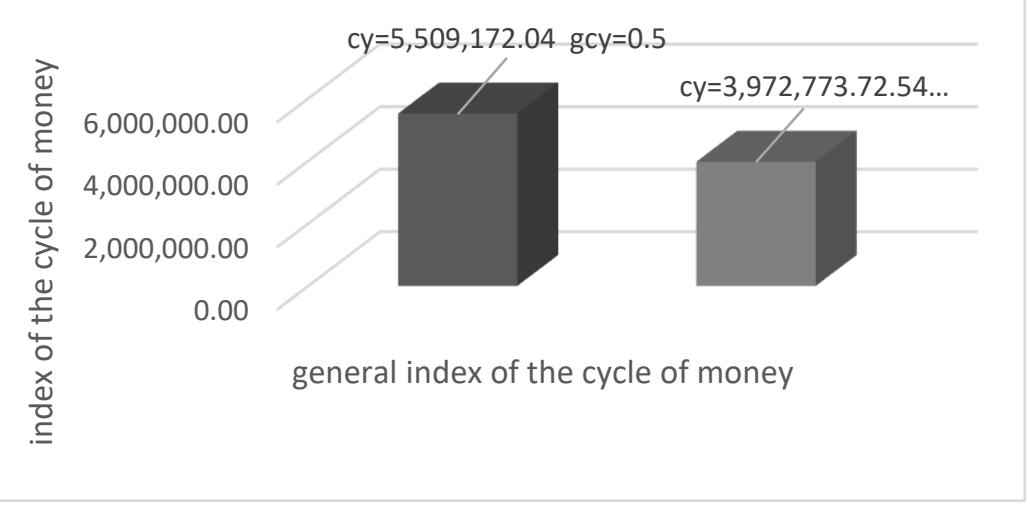

Figure 4. The cycle of money indexes (Source: author's compilation)

To the prior scheme is presented the combination of the index of the cycle of money with the case of the general index of the cycle of money. It is represented the affiliation between the global average indexes and Serbia's index. Serbia is part of the countries which are moderate according to the global average index of the cycle of money (both for the simple index and general index).

\section{Concluding remarks}

Based on the outcomes of the table, Serbia may be under, but near the worldwide average index of the cycle of money. Using Figure 3 and Figure 4 the index of the cycle of money is close to the worldwide average of the index of the cycle of money, displaying that Serbia's distribution of money is to a medium rate. Economies with low cycle of money are considered that are below the 0.2 general index cycle of money. The cycle of money of the country needs a better distribution of money. The losses of the local banks are to a moderate degree due to the fact an amount of money is excluded from the local financial system by worldwide transactions.

The interpretation is that this financial system belongs to the medium level of the cycle of money, then there is a medium dynamic, because the structure of the economy may be improved, with decrease taxes to the small and the medium companies, and increase of taxes to the bigger companies. Additionally, the bigger companies have to provide economic activities that smaller businesses can't support, then the authorities ought to imply low taxes to know-how companies and factories. Therefore, large companies must no longer replace smaller businesses' activities. The investments of a country are boosted by the increase in the distribution of money. A country with a well-based economic system is a country with a good cycle of money and therefore it can face an economic crisis. Serbia's economic system is under, but near the index of common GDP per capita, from 2012 to 2017 using the index of average GDP per capita.

The current model complies with the initial hypothesis, showing the distribution of money to Serbia's economy. Serbia's economic system has a tendency in the last years to have better reuse of money withinside the financial system than in the past, as tends to have closer characteristics to a financial system which complies better with the idea of the cycle of money. Finally, Serbia's financial dynamic is medium according to the worldwide average cycle of money. 


\section{Acknowledgements}

This research did not receive any specific grant from funding agencies in the public commercial, or not-for-profit sectors.

The author declares no competing interests.

\section{References}

Bank de France (2018). Costs and consequences of a trade war: A structural analysis. Policy paper.

Boland, L. A. (1991). The methodology of economic model building. London and New York: Routledge.

Challoumis, C. K. (2018a). Methods of controlled transactions and the behavior of companies according to the public and tax policy. ECONOMICS, De Gruyter, Sciendo, 6(1), 33-43. https://doi.org/10.2478/eoik-2018-0003

Challoumis, C. K. (2018b). The Keynesian theory and the theory of cycle of money. Hyperion, https://hej.hyperion.ro/articles/3(6) 2018/HEJ\%20nr3(6)_2018_A1Challoumis.pdf.

Challoumis, C. K. (2019a). The R.B.Q. (Rational, Behavioral and Quantified) Model. Retrieved from Ekonomika (Economics), 98(1), 6-18. https://doi.org/10.15388/ekon.2019.1.1

Challoumis, C. K. (2019b). Transfer pricing methods for services and the policy of fixed length principle. Economics and Business, 33(1), 222-232. https://doi.org/10.2478/eb-2019-0016

De Nederlandsche Bank (2018). Economic Developments and Outlook. Report 15.

Erceg, C., Prestipino, A., \& Raffo, A. (2018). The macroeconomic effects of trade policy. International Finance Discussion papers 1242.

Feinschreiber, R. (2004). Transfer pricing methods: An application guide. New Jersey: John Wiley \& Sons.

Helpman, E., \& Krugman, P. (1989). Trade policy and market structure. MIT Press.

IMF (2018). World Economic Outlook. Report.

IMF, World Bank, \& WTO. (2017). Making trade an engine of growth for all. Policy Paper.

King, E. (2009). Transfer pricing and corporate taxation problems: Practical implications and proposed solutions. Springer.

Lerner, A. (1936). The symmetry between export and import taxes. Economica, (3), 306-313.

Linde, J., \& Pescatori, A. (2017). The macroeconomic effects of trade tariffs: Revisiting. CEPR Discussion Papers 12534.

McKay, A., Nakamura, E., \& Steinsson, J. (2016). The power of forward guidance revisited. American Economic Review.

Meier, B. D., \& Rosenbaum, D. T. (2000). Making single mothers work: Recent tax and welfare policy and its effects. 53 (4).

OECD (2001). Transfer Pricing Guidelines for Multinational Enterprises and Tax Administrations. Paris: OECD.

OECD (2010). Review of comparability and of profit methods: revision of Chapters-III of the Transfer Pricing Guidelines. CTPA.

OECD (2018). Trade policy and the global economy - Scenario 2: Increasing tariffs.

OECD (July 2017). Transfer pricing guidelines for multinational enterprises and tax administrations. Paris: OECD Publishing. 
C. Challoumis - Index of the Cycle of Money: The Case of Serbia

Ossa, R. (2014). Trade wars and trade talks with data. American Economic Review, 104(12), 4104-4146.

Timothy, R. J. (2010). Fuzzy logic with engineering applications. John Wiley \& Sons, Ltd.

United Nations (2013). Practical manual on transfer pricing for developing countries. New York: United Nations Department of Economic \& Social Affairs.

Van Wijnbergen, S. (1987). Tariffs, employment and the current account: Real wage resistance and the macroeconomics of protectionism. Economic Review, 28(3), 691-706.

Wilson, J. D. (1986). A theory of interregional tax competition. Journal of Urban Economics, 19(3), 296315 .

Zax, J. S. (1988). Fringe benefits, income tax exemptions, and implicit subsides. Journal of Public Economics, 171-183. 